\title{
Data report: Monte Carlo correlation of sediment records from core and downhole log measurements at Sites U1337 and U1338 (IODP Expedition 321) ${ }^{1}$
}

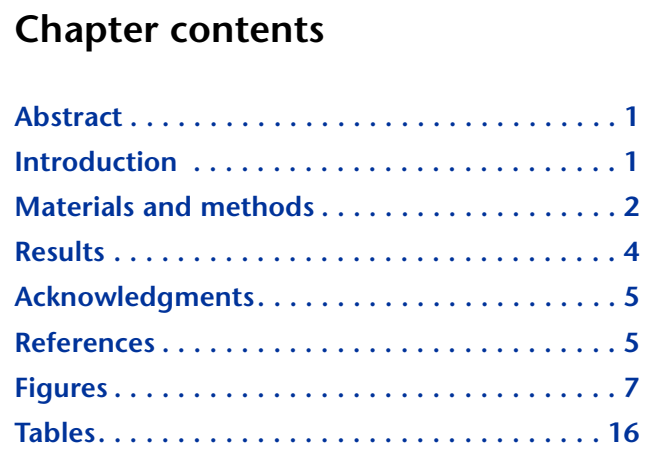

\footnotetext{
${ }^{1}$ Malinverno, A., 2013. Data report: Monte Carlo correlation of sediment records from core and downhole log measurements at Sites U1337 and U1338 (IODP Expedition 321). In Pälike, H., Lyle, M., Nishi, H., Raffi, I., Gamage, K., Klaus, A., and the Expedition 320/321 Scientists, Proc. IODP, 320/ 321: Tokyo (Integrated Ocean Drilling Program Management International, Inc.).

doi:10.2204/iodp.proc.320321.207.2013

${ }^{2}$ Lamont-Doherty Earth Observatory of Columbia University, PO Box 1000, 61 Route 9W, Palisades NY 10964-1000, USA.

alberto@Ideo.columbia.edu
}

1 1 2 4 .5 5 16
Alberto Malinverno ${ }^{2}$

(1)
This study uses an automated Monte Carlo algorithm to align core and log records at the same site and to determine site-to-site correlations. The distinguishing feature of the method is that it does not produce a single optimal correlation, but rather a sample of possible correlations that give a good match. The average of the samples gives the best correlation, and their variability measures the uncertainty inherent to the correlation.

The Monte Carlo method is first applied to correlate core splice and downhole log data at each site, so that the data can be referred to the same depth scale. The resulting correlation is close to a uniform 11\%-12\% expansion of the composite core depth scale, but local differences up to several meters mean that a detailed correlation is necessary to match small-scale sedimentary features. Once the downhole log data are placed onto the core depth scale, consistent site-to-site correlations between Sites U1337 and U1338 are determined by matching core and log data.

\section{Introduction}

Sediments deposited in the equatorial Pacific Ocean store some of the best long-term records of Earth's climate. These sediments record ocean-wide variations, as shown by the observation that in this region sediment physical properties correlate over large distances (Moore and Pälike, 2006). These lithostratigraphic correlations complement bio-, chemo-, and magnetostratigraphic correlations and assist in the construction of a common timescale. Integrated Ocean Drilling Program (IODP) Expeditions 320 and 321 (Pacific Equatorial Age Transect) sampled the sediment 
mound deposited near the paleoequator to validate and extend the astronomical calibration of the Cenozoic geologic timescale and to improve, date, and intercalibrate stratigraphic datums (see the "Expedition 320/321 summary" chapter [Pälike et al., 2010]).

This data report applies a Monte Carlo method to obtain a detailed lithostratigraphic correlation by matching two sediment records. The distinguishing feature of the method is that it does not produce a single optimal correlation, but rather a sample of possible correlations that result in a good match. The average of these samples gives the best correlation, and their variability measures the uncertainty that is inherent to the correlation, highlighting intervals where the match is relatively poor and the correlation less reliable.

The method is applied to high-resolution bulk density measurements from core samples and downhole logs from Expedition 321 Sites U1337 and U1338, which targeted the early Miocene to present time interval and were drilled $600 \mathrm{~km}$ apart (see the "Expedition 320/321 summary" chapter [Pälike et al., 2010]). A combination of core and log measurements best constrains site-to-site correlations, but complications occur because these two data types are placed on different depth scales. The cumulative length of drill pipe is used for core depth, whereas the measured length of the wireline cable determines depth in downhole logs. Moreover, to obtain as complete a record as possible, a composite depth scale is constructed by splicing core sections taken from different holes at the same site. This process typically expands the actual thickness of the cored interval by 10\%-15\% (Lisiecki and Herbert, 2007; Westerhold et al., 2012). Reconciling these different depth scales requires a detailed correlation to precisely align the high-resolution core and $\log$ records at each site prior to site-to-site correlation. The Monte Carlo method is applied to first correlate core and downhole log data at each site, so that all data are placed on the same depth scale. Core and downhole log data are then used to obtain a reliable lithostratigraphic correlation between the two sites.

\section{Materials and methods}

\section{Core and downhole log data}

The data used here consist of density core splices and downhole log data obtained at Sites U1337 and U1338. The density core splices were obtained from gamma ray attenuation (GRA) densities measured on whole-round core sections on the R/V JOIDES Resolu- tion. The splices were painstakingly constructed by overlapping GRA density records from three holes at each site (Wilkens et al., in press). The downhole density log data were measured using the Schlumberger Hostile Environment Litho-Density Sonde (HLDS) wireline logging tool in Holes U1337A and U1338B.

The core splice and downhole log data have different depth coverages and measurement resolutions. Although the core splices span the full interval drilled, there are no downhole log data from the top of the hole. This is because the drill pipe is typically lowered to $\sim 80$ meters below seafloor (mbsf) during logging to avoid the near-seafloor interval where the borehole is enlarged and irregular. The GRA data have a nominal resolution of $<1 \mathrm{~cm}$ (measurements were taken every $2.5 \mathrm{~cm}$ ), whereas the downhole density $\log$ has a vertical resolution of $\sim 20 \mathrm{~cm}$. Detailed comparisons, however, show that the difference in resolution is minor and that the decimeterscale sedimentary features that are most useful for correlation are usually well resolved in both data sets. More details on the GRA and log measurements are in the "Methods" chapter (Expedition 320/321 Scientists, 2010).

A major complication that prevents immediate correlation of core splice and downhole log data is that they are referred to different depth scales. The current IODP terminology (www.iodp.org/doc_download/ 3171-iodpdepthscaleterminologyv2) defines the depth scale of the core splices as composite core depth below seafloor (CCSF) and the depth scale of the processed downhole logs as wireline matched depth below seafloor (WMSF). The CCSF depth scale is determined starting from the seafloor by splicing the GRA density records measured in different core sections from different holes. The WMSF depth scale is determined by referring the depth measured by the wireline cable length to the seafloor (typically defined by a step change in the natural gamma radiation $\log$ ). The wireline depths measured in different logging runs are then "matched" by small adjustments that align the natural gamma radiation $\log$ acquired in each run.

\section{Reversible jump Monte Carlo sampling}

The process of determining a mapping function that relates depth in one record to depth in another is illustrated in Figure F1. Solutions in the literature include the nonlinear optimization methods of Martinson et al. (1982) and Brüggemann (1992) and the exhaustive search method of Lisiecki and Lisiecki (2002). Whereas these approaches focus on obtaining an optimal result, the Monte Carlo method de- 
scribed here also quantifies the uncertainty of the inferred mapping function. The mapping function will have a large uncertainty in intervals where the match between the records remains poor while the mapping function can vary significantly. This measure of uncertainty is important to quantify the accuracy of the correlation.

For comparison, the two records are rescaled to zero mean and unit standard deviation and their match is measured by a residual standard deviation (the standard deviation of the difference between the records). The mapping function is defined at any depth by linear interpolation between a number of nodes (Fig. F1). The problem is then to determine sets of nodes that give a good match between the two records (i.e., a small residual standard deviation). An additional requirement is that the gradient of the mapping function should not contain large fluctuations (Brüggemann, 1992; Lisiecki and Lisiecki, 2002). In the context of this study, large changes in the gradient of the mapping function would correspond to unrealistic measured depth errors (for core-log correlations at the same site) or excessive differences in sedimentation rate (for correlations between sites).

The requirements of a smooth mapping function and of a good data match can be combined in a Bayesian formulation, which defines a prior distribution and a likelihood of the mapping function. The value of the prior will be higher for mapping functions whose gradients have smaller fluctuations about their average. Mapping functions that result in closer matches between the records will have a higher value of likelihood. The posterior distribution of mapping functions is proportional to the product of prior and likelihood and balances the competing requirements of a smooth mapping function and of a close match of the records. This Bayesian formulation has been widely used in geophysical inverse problems (Tarantola and Valette, 1982; Jackson and Matsu'ura, 1985; Duijndam, 1988; Tarantola, 2005) and has been applied to cycle stratigraphy (Malinverno et al., 2010) and timescale construction (Malinverno et al., 2012).

A key feature of the correlation problem in Figure F1 is that the number of nodes in the mapping function is one of the unknowns. In the apt terminology of Sambridge et al. (2006), this is a "trans-dimensional" inverse problem. Green (1995) devised a general algorithm that can be applied to these problems, called reversible jump Markov chain Monte Carlo sampling. In the correlation problem treated here, the reversible jump algorithm begins from a starting set of nodes that define an initial approximate correlation and continues as follows:

1. Propose a "candidate" mapping function by

- Perturbing the coordinates of an existing node,

- Adding a new node, or

- Deleting an existing node (except for the starting nodes).

2. Accept or reject the candidate mapping function on the basis of its posterior probability as in the Metropolis-Hastings algorithm (Metropolis et al., 1953; Hastings, 1970). The posterior probability is higher for mapping functions that

- Result in a better match (i.e., a smaller residual standard deviation) and

- Have smaller fluctuations in their gradient.

3. Repeat from step 1.

This simple algorithm asymptotically draws samples from the posterior distribution of mapping functions. For examples of reversible jump sampling applied to geophysical inverse problems, see Malinverno (2002), Malinverno and Leaney (2005), Sambridge et al. (2006), Bodin and Sambridge (2009), and Piana Agostinetti and Malinverno (2010).

A sequence of 2000 sampling iterations of the reversible jump algorithm is shown in Figure F2. The residual standard deviation, which measures how close the match is between the two records, decreases as sampling progresses and becomes nearly constant after $\sim 1000$ iterations. The likelihood function correspondingly increases. On the other hand, the value of the prior distribution decreases, mostly because the number of nodes in the mapping function increases to achieve a better data match. The decrease in the prior distribution is compensated by a much larger increase in the likelihood, meaning that the cost of adding more nodes is much less than the gain because of better data matching so that the posterior probability of the mapping function increases during the sampling.

The likelihood function and the prior distribution are controlled by target standard deviations of the data residuals and of the mapping function gradient, respectively. The relative size of these target standard deviations will weigh the competing needs of matching the data and minimizing changes in the mapping function gradient. The target standard deviation of the data residuals is set to be one of the unknown parameters as in a hierarchical Bayes formulation (Malinverno and Briggs, 2004). This means that this target standard deviation does not need to be predetermined; the algorithm samples it by iteratively perturbing its value and effectively adjusts it to 
match the actual residual standard deviation achieved by the sampling (Fig. F2). Numerical experiments showed that a target standard deviation of the mapping function gradient equal to $20 \%$ of the mean gradient resulted in a reasonable trade-off between data match and smoothness of the mapping function.

The results described below were all obtained from 100 independent runs of the reversible jump algorithm. Each run consisted of 2000 sampling iterations. The mean mapping function and its standard deviation were determined from the 100 mapping functions obtained at the end of each run. This multiple run strategy minimizes the effect of sampling secondary modes of the posterior distribution. Although the Monte Carlo method will asymptotically sample the global mode of the posterior distribution, the sampling can still remain for a large number of iterations in a secondary mode.

\section{Results}

\section{Correlations within Sites U1337 and U1338}

The first step is to correlate core splices and downhole logs at Sites U1337 and U1338 so that both records can be placed on the same depth scale (Fig. F1). The Monte Carlo sampling started from eight nodes at Site U1337 and four nodes at Site U1338. These starting nodes were chosen to match major features in the two records; in particular, they correlate a thin 16-40 cm chert interval that was imaged in the downhole logs and that had poor core recovery. This distinctive "baby chert" was located at 240 $\mathrm{m}$ WMSF at Site U1337 and $281.6 \mathrm{~m}$ WMSF at Site U1338 (see Fig. F47 in the "Expedition 320/321 summary" chapter [Pälike et al., 2010]).

The estimated mapping functions are close to a constant expansion of the composite core depth scale that is $\sim 12 \%$ at Site U1337 and $\sim 11 \%$ at Site U1338 (Figs. F3, F4). These values are consistent with the 9\%-16\% composite depth scale expansions determined for Expedition 320 Sites U1331-U1334 by Westerhold et al. (2012). However, differences between the estimated mapping functions and constant core expansion reach about $\pm 5 \mathrm{~m}$ at Site U1337 and $\pm 2 \mathrm{~m}$ at Site U1338 (Figs. F3, F4). Although the magnitude of these differences is not the same, the overall pattern is similar at the two sites. A possible explanation may be lithology variations. The shallower half of the interval drilled at both sites contains a sizable siliceous component, whereas the deeper half is dominated by calcareous nannofossil ooze grading downward to chalk. These different lithologies may result in different core expansions. On the other hand, these differences are relative to the downhole log depth scale, which may itself be affected by errors (e.g., due to stretching of the wireline cable). Whatever the cause, results in Figures F3 and F4 show that a detailed correlation that goes beyond a constant core expansion is necessary to match small-scale features in the core and downhole log data.

Figures F5 and F6 show the close match of core splice and downhole log data that is achieved when both records are put on the same depth scale. The match is generally excellent, with the exception of the deepest intervals below $\sim 350 \mathrm{~m} \mathrm{WMSF}$ or $\sim 400 \mathrm{~m}$ CCSF. Density variations are smaller in these deep intervals, making correlations more ambiguous. Also, in the deeper hole intervals, core recovery was lower and core conditions were poorer, making the splice data less robust. Outside of these deep intervals, the uncertainties of the mapping functions are generally $<1$ m (1 standard deviation; Figs. F3, F4).

\section{Correlations between Sites U1337 and U1338}

Figures F7 and F8 show the results of correlating core splice data and downhole log data between Sites U1337 and U1338. To obtain correlations that could be directly compared, the downhole log data were placed on the composite core depth scale (CCSF) using the mapping functions obtained previously (Figs. F3, F4). The Monte Carlo sampling started from six nodes for the core splice correlation and four nodes for the downhole log correlation. The site-to-site mapping functions obtained for core splice and downhole log data are illustrated in Figure F9. Once the two data sets are placed on the same depth scale, the site-to-site correlations are entirely consistent.

These lithostratigraphic correlations have the smallest uncertainties in the intervals 130-330 m CCSF at Site U1337 and 140-380 m CCSF at Site U1338. In these intervals, the match of small-scale features in the two records is excellent (Figs. F7, F8). The uncertainties of the mapping function outside this wellcorrelated interval reach several meters ( 1 standard deviation; Fig. F9). These uncertainties quantify the confidence of correlations based on lithostratigraphy. For example, a stratigraphic event observed at $400 \mathrm{~m}$ CCSF at Site U1338 can be correlated to a depth of $346 \mathrm{~m}$ CCSF at Site U1337, but this correlation has an inherent uncertainty of about $\pm 5 \mathrm{~m}$ ( 1 standard deviation). To assist in building a composite sedimentary record in the equatorial Pacific Ocean, the mapping functions that correlate Sites U1337 and U1338 (Fig. F9) are provided in Table T1 (core splice data) and Table T2 (downhole log data). 


\section{Acknowledgments}

This research was supported by grant JOI-T321A31 of the U.S. Science Support Program and used samples and data provided by the Integrated Ocean Drilling Program. The efforts of the JOIDES Resolution shipboard and drilling personnel and of the science parties of IODP Expeditions 320 and 321 are gratefully acknowledged. Special thanks to Roy Wilkens for providing the core density splice data used in this study.

\section{References}

Bodin, T., and Sambridge, M., 2009. Seismic tomography with the reversible jump algorithm. Geophys. J. Int., 178(3):1411-1436. doi:10.1111/j.1365-

246X.2009.04226.X

Brüggemann, W., 1992. A minimal cost function method for optimizing the age-depth relation of deep-sea sediment cores. Paleoceanography, 7(4):467-487. doi:10.1029/92PA01235

Duijndam, A.J.W., 1988. Bayesian estimation in seismic inversion, Part I: Principles. Geophys. Prosp., 36(8):878898. doi:10.1111/j.1365-2478.1988.tb02198.x

Expedition 320/321 Scientists, 2010. Methods. In Pälike, H., Lyle, M., Nishi, H., Raffi, I., Gamage, K., Klaus, A., and the Expedition 320/321 Scientists, Proc. IODP, 320/ 321: Tokyo (Integrated Ocean Drilling Program Management International, Inc.). doi:10.2204/

iodp.proc.320321.102.2010

Green, P.J., 1995. Reversible jump Markov chain Monte Carlo computation and Bayesian model determination. Biometrika, 82(4):711-732. doi:10.1093/biomet/ 82.4.711

Hastings, W.K., 1970. Monte Carlo sampling methods using Markov chains and their applications. Biometrika, 57(1):97-109. doi:10.1093/biomet/57.1.97

Jackson, D.D., and Matsu'ura, M., 1985. A Bayesian approach to nonlinear inversion. J. Geophys. Res., [Solid Earth], 90(B1):581-591. doi:10.1029/JB090iB01p00581

Lisiecki, L.E., and Herbert, T.D., 2007. Automated composite depth scale construction and estimates of sediment core extension. Paleoceanography, 22(4):PA4213. doi:10.1029/2006PA001401

Lisiecki, L.E., and Lisiecki, P.A., 2002. Application of dynamic programming to the correlation of paleoclimate records. Paleoceanography, 17(4):1049. doi:10.1029/2001PA000733

Malinverno, A., 2002. Parsimonious Bayesian Markov chain Monte Carlo inversion in a nonlinear geophysical problem. Geophys. J. Int., 151(3):675-688. doi:10.1046/ j.1365-246X.2002.01847.x

Malinverno, A., and Briggs, V.A., 2004. Expanded uncertainty quantification in inverse problems: hierarchical Bayes and empirical Bayes. Geophysics, 69(4):1005-1016. doi:10.1190/1.1778243
Malinverno, A., Erba, E., and Herbert, T.D., 2010. Orbital tuning as an inverse problem: chronology of the early Aptian oceanic anoxic Event 1a (Selli Level) in the Cismon APTICORE. Paleoceanography, 25(2):PA2203. doi:10.1029/2009PA001769

Malinverno, A., Hildebrandt, J., Tominaga, M., and Channell, J.E.T., 2012. M-sequence geomagnetic polarity time scale (MHTC12) that steadies global spreading rates and incorporates astrochronology constraints. J. Geophys. Res., [Solid Earth], 117(B6):B06104. doi:10.1029/ 2012JB009260

Malinverno, A., and Leaney, W.S., 2005. Monte-Carlo Bayesian look-ahead inversion of walkaway vertical seismic profiles. Geophys. Prosp., 53(5):689-703. doi:10.1111/j.1365-2478.2005.00496.x

Martinson, D.G., Menke, W., and Stoffa, P., 1982. An inverse approach to signal correlation. J. Geophys. Res., [Solid Earth], 87(B6):4807-4818. doi:10.1029/ JB087iB06p04807

Metropolis, N., Rosenbluth, A.W., Rosenbluth, M.N., Teller, A.H., and Teller, E., 1953. Equation of state calculations by fast computing machines. J. Chem. Phys., 21(6):10871092. doi:10.1063/1.1699114

Moore, T., and Pälike, H., 2006. Time is of the essence. Oceanography, 19(4):22-27. doi:10.5670/ oceanog.2006.01

Pälike, H., Nishi, H., Lyle, M., Raffi, I., Gamage, K., Klaus, A., and the Expedition 320/321 Scientists, 2010. Expedition 320/321 summary. In Pälike, H., Lyle, M., Nishi, H., Raffi, I., Gamage, K., Klaus, A., and the Expedition 320/ 321 Scientists, Proc. IODP, 320/321: Tokyo (Integrated Ocean Drilling Program Management International, Inc.). doi:10.2204/iodp.proc.320321.101.2010

Piana Agostinetti, N., and Malinverno, A., 2010. Receiver function inversion by trans-dimensional Monte Carlo sampling. Geophys. J. Int., 181(2):858-872. doi:10.1111/ j.1365-246X.2010.04530.x

Sambridge, M., Gallagher, K., Jackson, A., and Rickwood, P., 2006. Trans-dimensional inverse problems, model comparison, and the evidence. Geophys. J. Int., 167(2):528-542. doi: $10.1111 /$ j.1365246X.2006.03155.x

Tarantola, A., 2005. Inverse Problem Theory and Methods for Model Parameter Estimation: Philadelphia (Soc. Ind. Appl. Math.). doi:10.1137/1.9780898717921

Tarantola, A., and Valette, B., 1982. Inverse problems = quest for information. J. Geophys., 50:159-170. http:// www.ipgp.fr/ tarantola/Files/Professional/ Papers_PDF/IP_QI_original.pdf

Westerhold, T., Röhl, U., Wilkens, R., Pälike, H., Lyle, M., Jones, T.D., Bown, P., Moore, T., Kamikuri, S., Acton, G., Ohneiser, C., Yamamoto, Y., Richter, C., Fitch, P., Scher, H., Liebrand, D., and the Expedition 320/321 Scientists, 2012. Revised composite depth scales and integration of IODP Sites U1331-U1334 and ODP Sites 1218-1220. In Pälike, H., Lyle, M., Nishi, H., Raffi, I., Gamage, K., Klaus, A., and the Expedition 320/321 Scientists, Proc. IODP, 320/321: Tokyo (Integrated Ocean Drilling Pro- 
gram Management International, Inc.). doi:10.2204/ iodp.proc.320321.201.2012

Wilkens, R.H., Dickens, G.R., Tian, J., Backman, J., and the Expedition 320/321 Scientists, in press. Data report: revised composite depth scales for Sites U1336, U1337, and U1338. In Pälike, H., Lyle, M., Nishi, H., Raffi, I., Gamage, K., Klaus, A., and Expedition 320/321 Scien- tists, Proc. IODP, 320/321: Tokyo (Integrated Ocean Drilling Program Management International, Inc.).

Initial receipt: 21 June 2012

Acceptance: 14 December 2012

Publication: 19 February 2013

MS 320321-207 
Figure F1. A spliced core density record (red) can be closely correlated to a downhole density log (black); correlations of discrete features are shown by dashed gray lines. The conversion between core depth and log depth is given by a mapping function (thick gray curve) defined by a few nodes (gray dots).

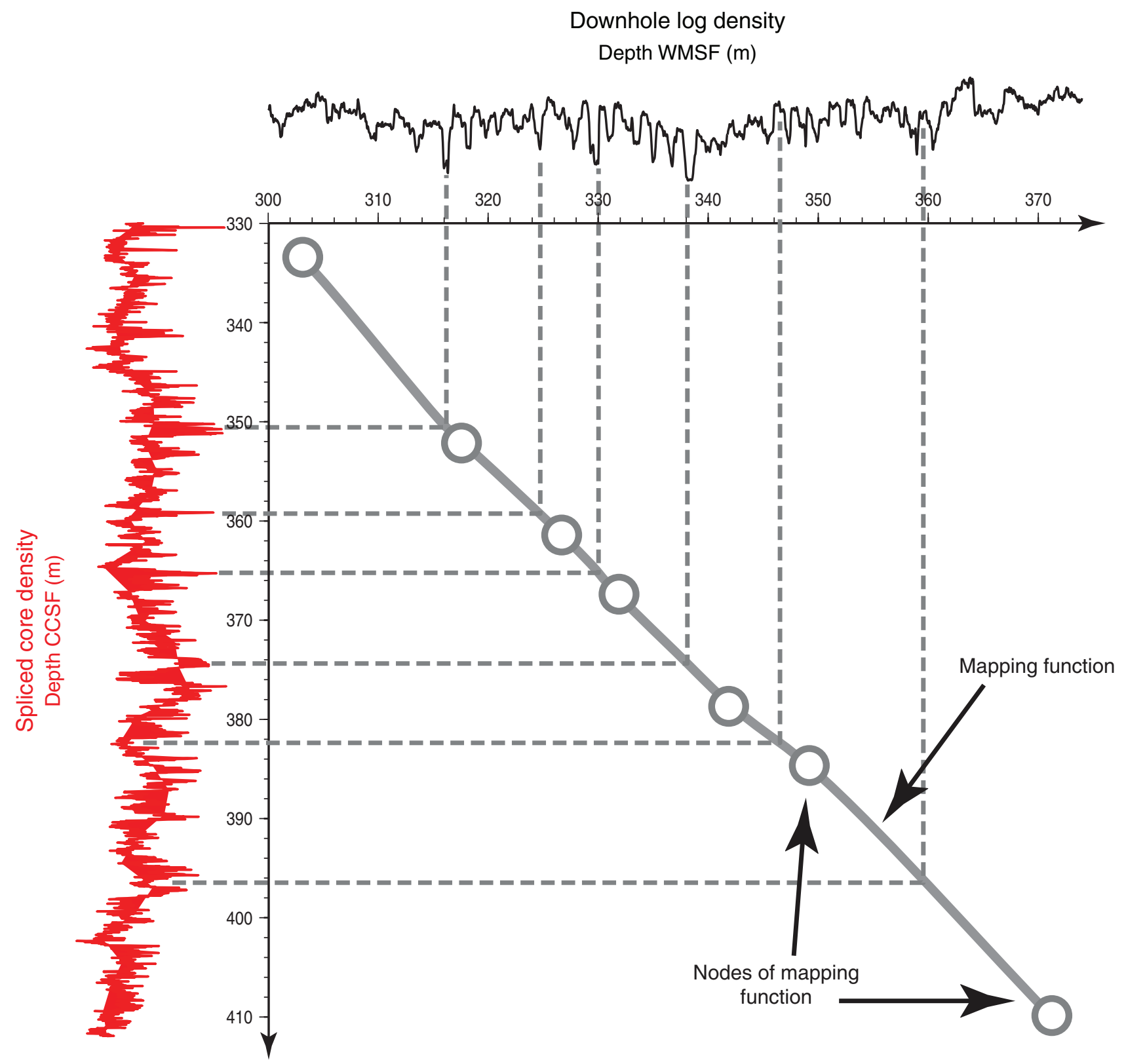


Figure F2. Progress of the reversible jump Monte Carlo algorithm in 2000 iterations. The residual standard deviation, which measures the mismatch between the two records, progressively decreases and the likelihood correspondingly increases. The red line shows the value of the target residual standard deviation, which is one of the unknown parameters and is adjusted by the algorithm during sampling. The value of the prior distribution decreases as the number of nodes necessary to improve the match between the two records increases.
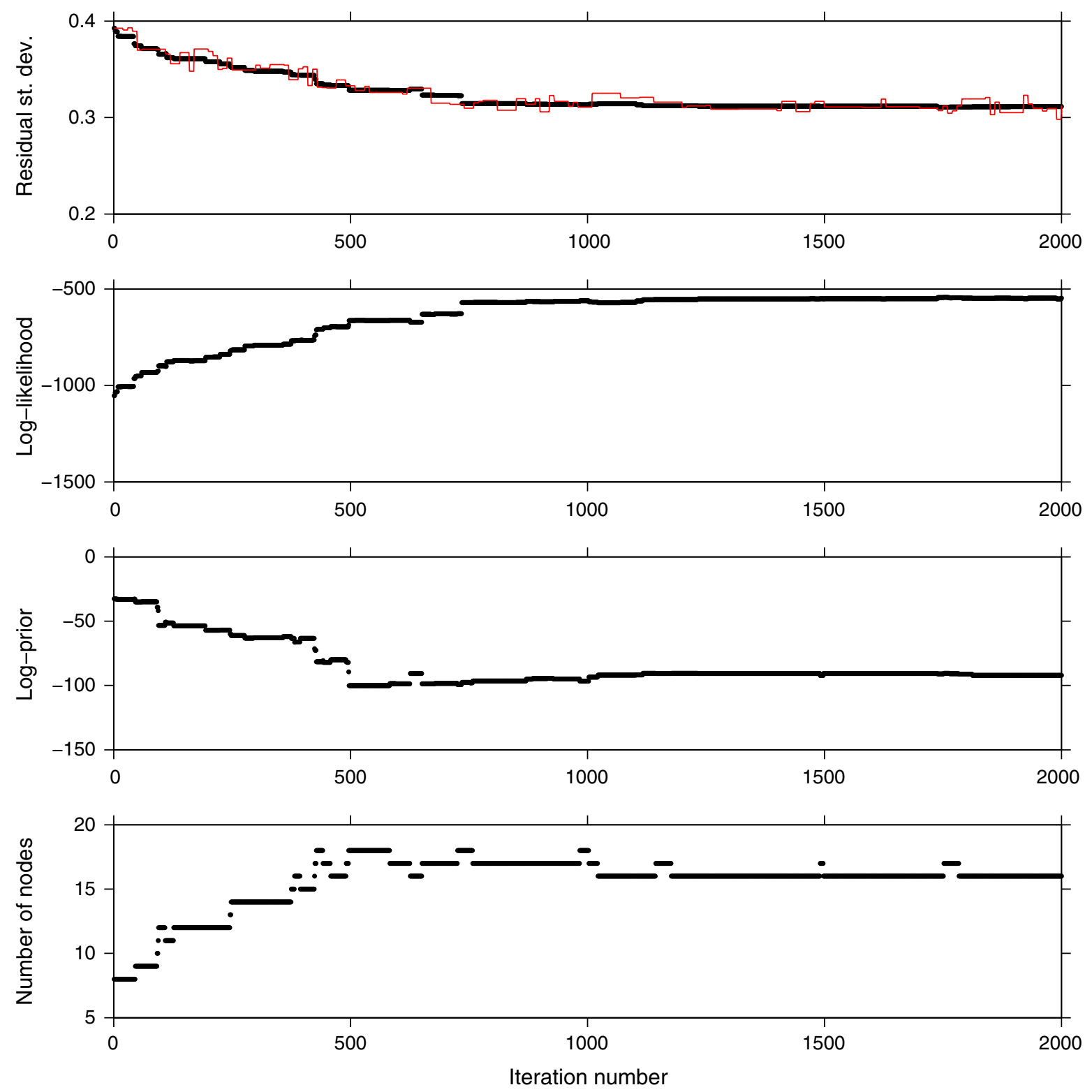
Figure F3. Mapping function between core splice and downhole log data (top) and residual of mapping function over the average core expansion (bottom) at Site U1337. The average mapping function is shown by a thick red line, and uncertainty bounds ( \pm 1 standard deviation) by thin red lines. The thick blue dashed line shows the average core expansion, and the gray dots are the starting nodes for the correlation.

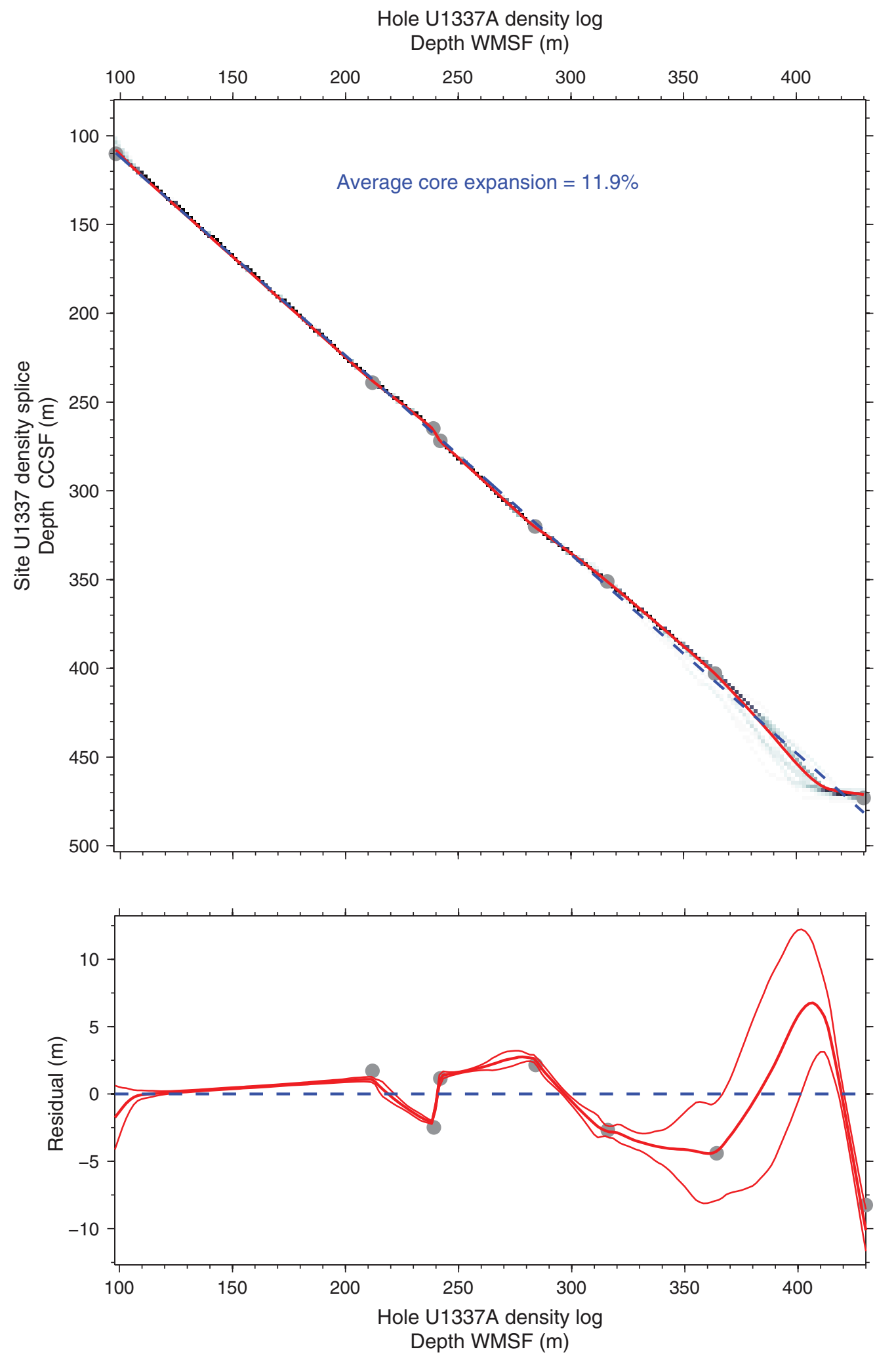


Figure F4. Mapping function between core splice and downhole log data (top) and residual of mapping function over the average core expansion (bottom) at Site U1338. The average mapping function is shown by a thick red line, and uncertainty bounds ( \pm 1 standard deviation) by thin red lines. The thick blue dashed line shows the average core expansion, and the gray dots are the starting nodes for the correlation.
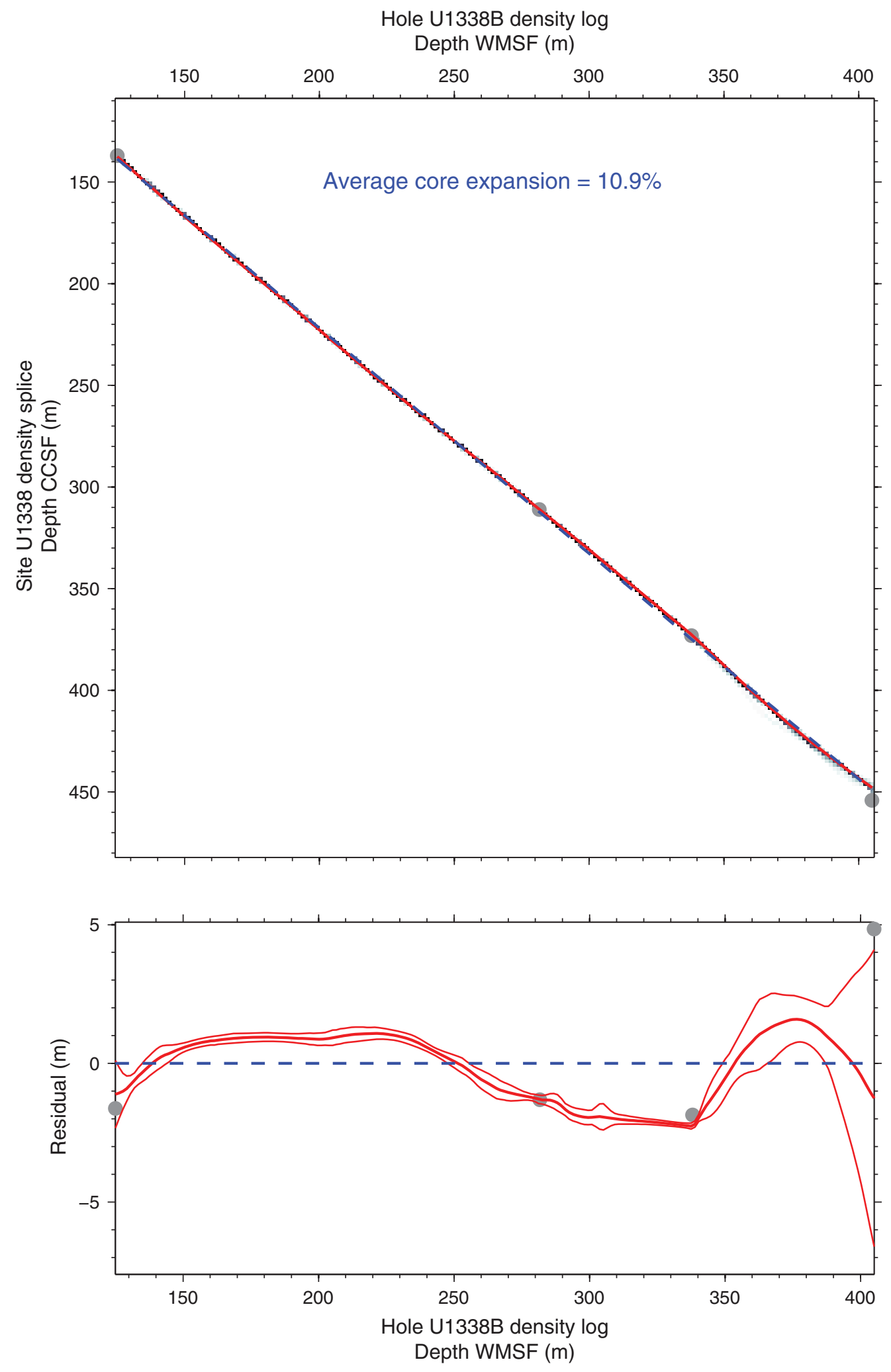
Figure F5. Core splice (red) and downhole log data (black) at Site U1337 plotted on the same depth scale from the mapping function in Figure F3.
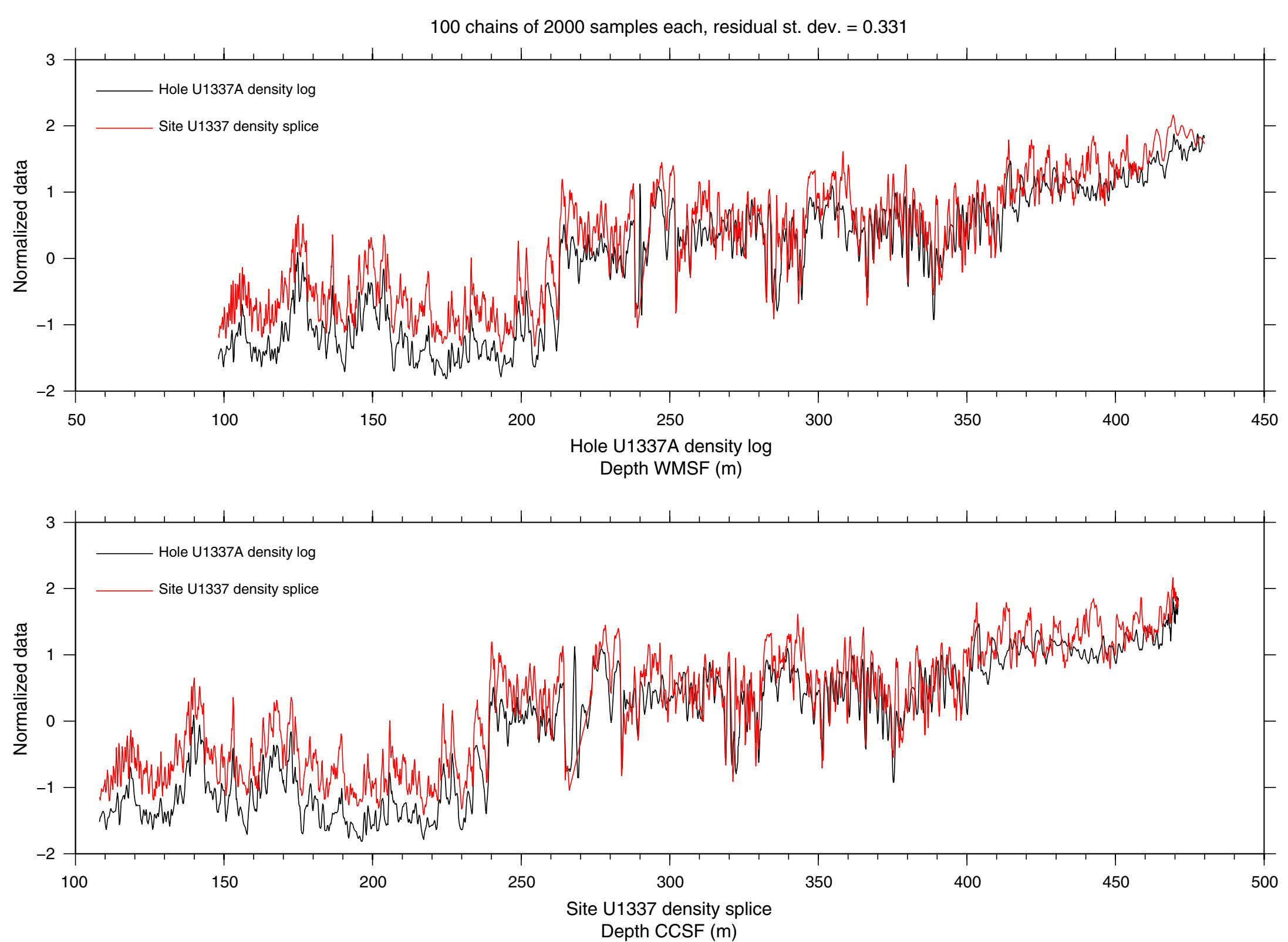
Figure F6. Core splice (red) and downhole log data (black) at Site U1338 plotted on the same depth scale from the mapping function in Figure F4.

100 chains of 2000 samples each, residual st. dev. $=0.311$
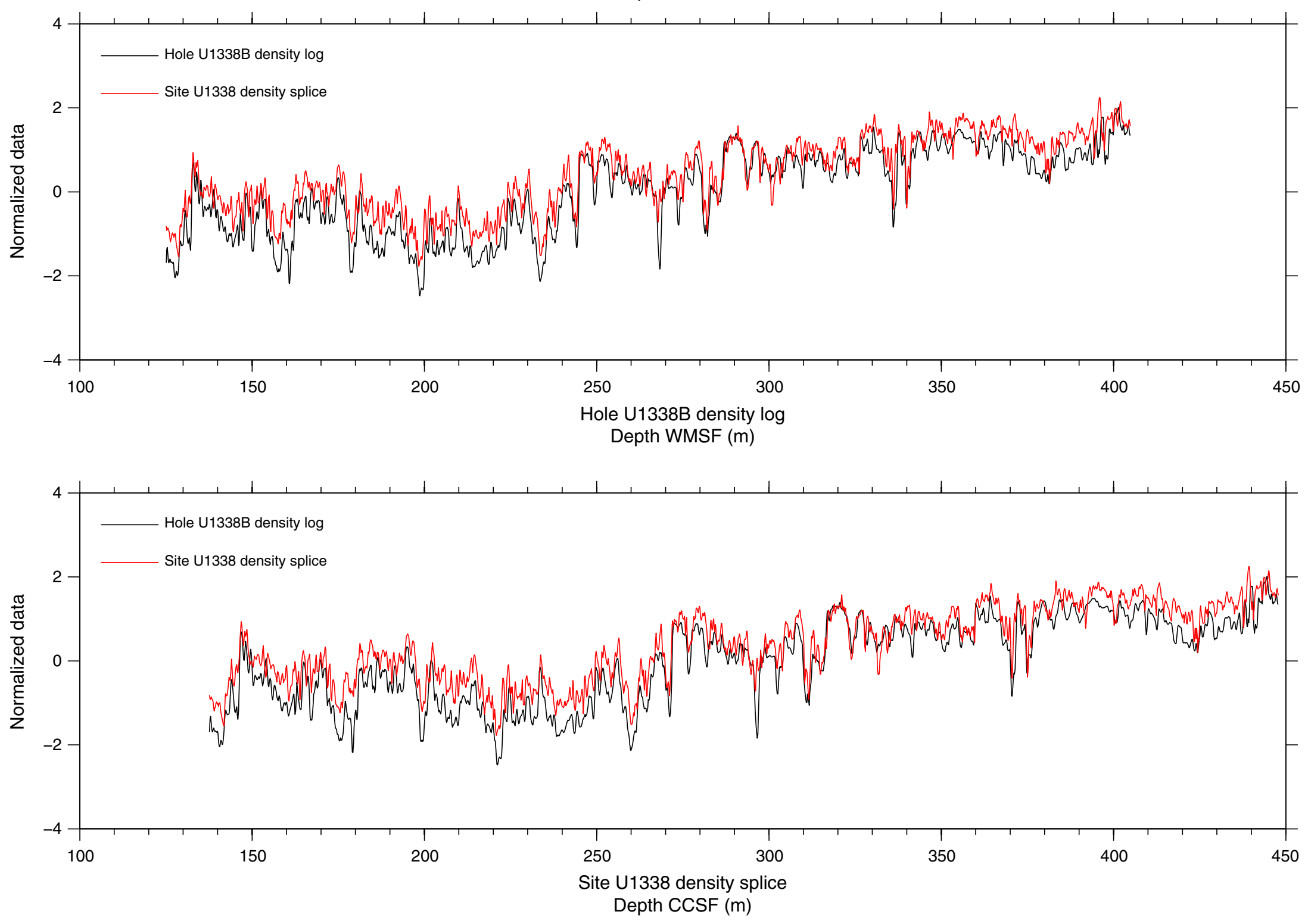
Figure F7. Results of Monte Carlo correlation of core splice records between Sites U1337 (red) and U1338 (black). The core splice data are plotted on the same depth scale (m CCSF at Site U1337 and U1338).
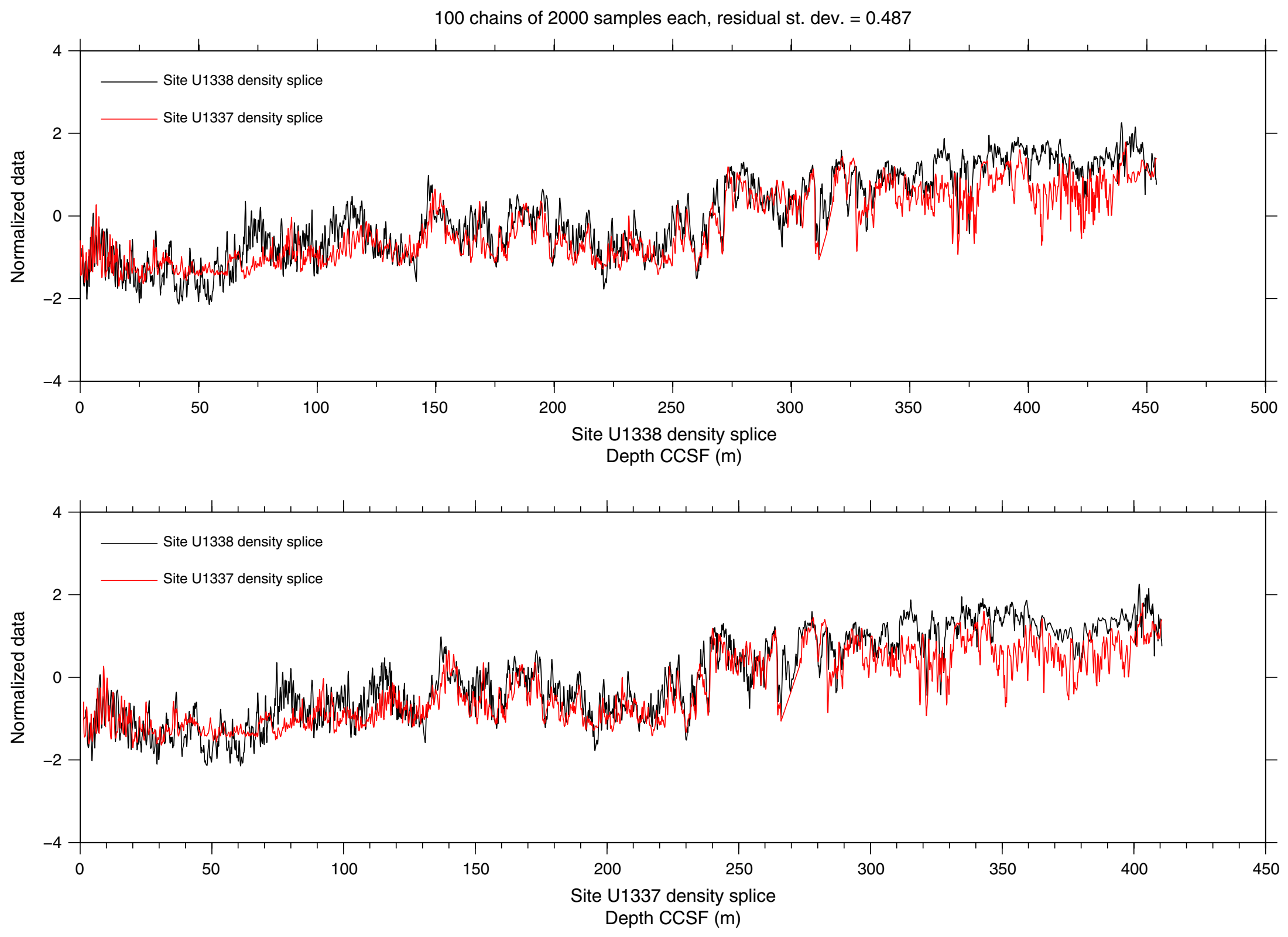
Figure F8. Results of Monte Carlo correlation of downhole log records between Sites U1337 (red) and U1338 (black). The downhole log data are plotted on the same depth scale (m CCSF at Site U1337 and U1338).
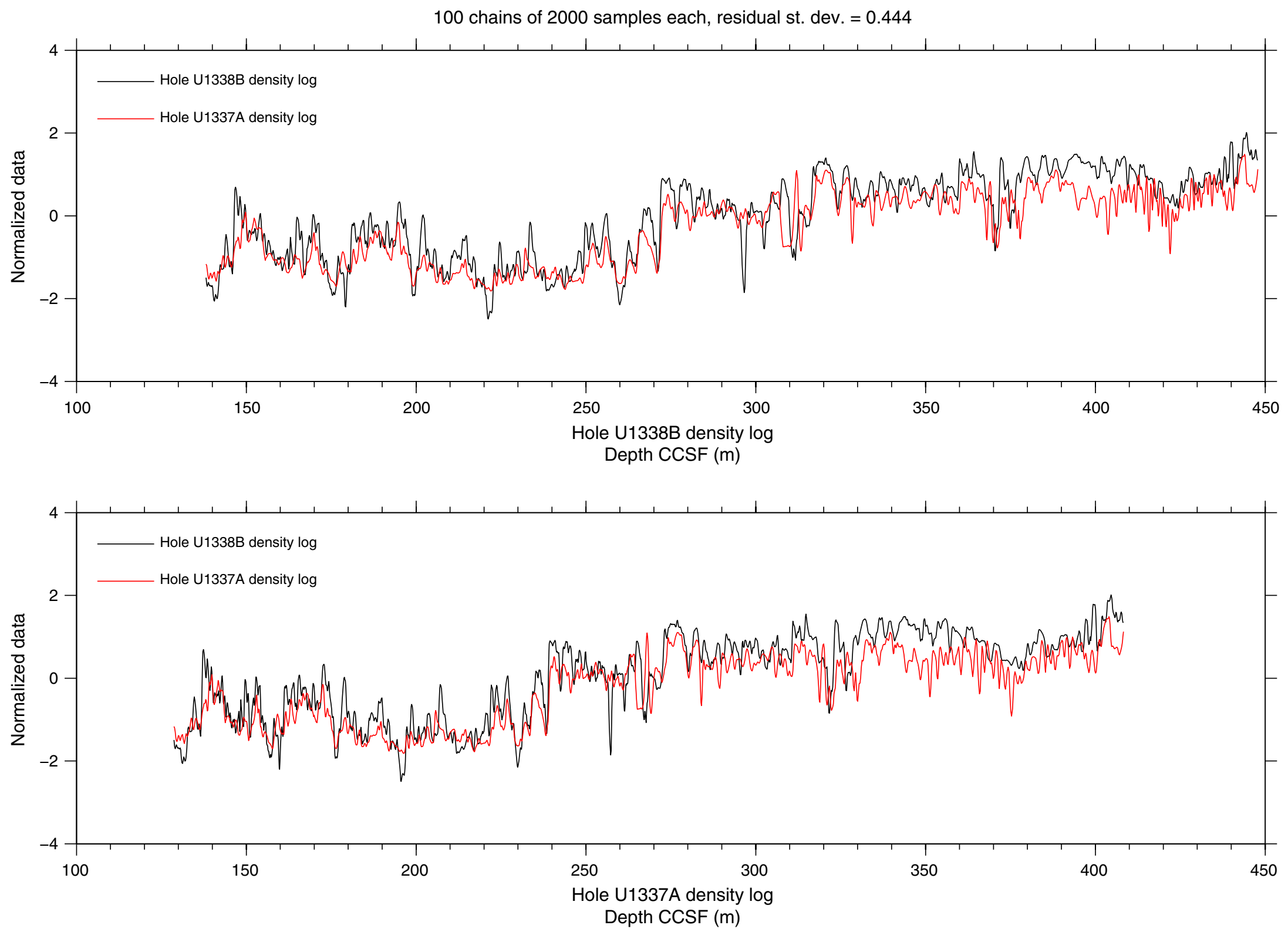
Figure F9. Mapping functions that correlate CCSF depths of core splice (red) and downhole log data (blue) between Sites U1337 and U1338. The light red and light blue regions show the uncertainty bands of the mapping functions ( \pm 1 standard deviation).

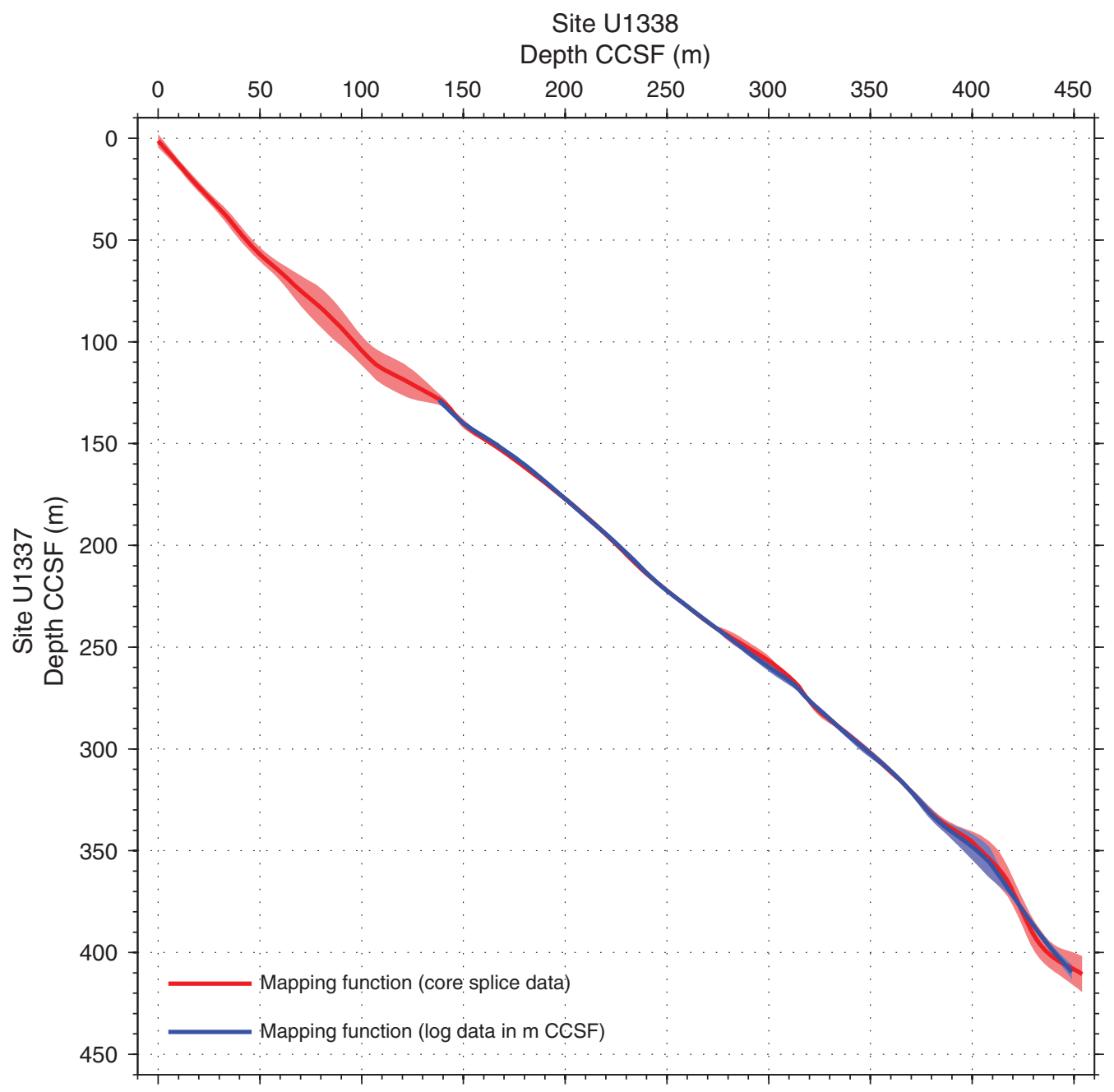


Table T1. Mapping function that correlates depths in the core density splices of Sites U1337 and U1338. (Continued on next page.)

\begin{tabular}{|c|c|c|}
\hline $\begin{array}{l}\text { Site U1338 } \\
\text { splice depth } \\
\text { (m CCSF) }\end{array}$ & $\begin{array}{l}\text { Site U1337 } \\
\text { splice depth } \\
\text { (m CCSF) }\end{array}$ & $\begin{array}{c}\text { Site U1337 } \\
\text { standard deviation } \\
(\mathrm{m})\end{array}$ \\
\hline 0 & 1.28388 & 3.31408 \\
\hline 2.28141 & 3.84603 & 3.00754 \\
\hline 4.56281 & 6.41747 & 2.7483 \\
\hline 6.84422 & 9.00798 & 2.4761 \\
\hline 9.12563 & 11.6412 & 2.33072 \\
\hline 11.407 & 14.3104 & 2.30436 \\
\hline 13.6884 & 16.9884 & 2.41982 \\
\hline 15.9698 & 19.6142 & 2.58173 \\
\hline 18.2513 & 22.1322 & 2.56567 \\
\hline 20.5327 & 24.5728 & 2.46581 \\
\hline 22.8141 & 26.9531 & 2.46445 \\
\hline 25.0955 & 29.2971 & 2.59239 \\
\hline 27.3769 & 31.6824 & 2.72611 \\
\hline 29.6583 & 34.0662 & 2.97691 \\
\hline 31.9397 & 36.4646 & 3.23703 \\
\hline 34.2211 & 39.0765 & 3.48905 \\
\hline 36.5025 & 41.8469 & 3.73096 \\
\hline 38.7839 & 44.682 & 3.83419 \\
\hline 41.0653 & 47.4388 & 3.64707 \\
\hline 43.3467 & 50.0899 & 3.63056 \\
\hline 45.6281 & 52.6086 & 3.48884 \\
\hline 47.9095 & 55.0019 & 3.49701 \\
\hline 50.191 & 57.1852 & 3.4782 \\
\hline 52.4724 & 59.2051 & 3.4671 \\
\hline 54.7538 & 61.1676 & 3.56511 \\
\hline 57.0352 & 63.1005 & 3.79647 \\
\hline 59.3166 & 65.0634 & 4.20693 \\
\hline 61.598 & 67.0955 & 4.77488 \\
\hline 63.8794 & 69.194 & 5.47067 \\
\hline 66.1608 & 71.3026 & 6.22947 \\
\hline 68.4422 & 73.4713 & 6.97877 \\
\hline 70.7236 & 75.5712 & 7.66733 \\
\hline 73.005 & 77.5344 & 8.27714 \\
\hline 75.2864 & 79.3701 & 8.80967 \\
\hline 77.5678 & 81.1948 & 9.30452 \\
\hline 79.8492 & 83.1502 & 9.55819 \\
\hline 82.1307 & 85.2876 & 9.68201 \\
\hline 84.4121 & 87.5345 & 9.69717 \\
\hline 86.6935 & 89.8244 & 9.5662 \\
\hline 88.9749 & 92.1395 & 9.19264 \\
\hline 91.2563 & 94.5385 & 8.69128 \\
\hline 93.5377 & 97.0311 & 8.18219 \\
\hline 95.8191 & 99.5897 & 7.70321 \\
\hline 98.1005 & 102.159 & 7.37389 \\
\hline 100.382 & 104.678 & 7.16303 \\
\hline 102.663 & 107.074 & 7.15388 \\
\hline 104.945 & 109.331 & 7.36019 \\
\hline 107.226 & 111.239 & 7.60291 \\
\hline 109.508 & 112.766 & 7.76307 \\
\hline 111.789 & 114.077 & 7.87423 \\
\hline 114.07 & 115.269 & 7.94462 \\
\hline 116.352 & 116.425 & 7.98157 \\
\hline 118.633 & 117.556 & 7.95899 \\
\hline 120.915 & 118.726 & 7.81833 \\
\hline 123.196 & 120.006 & 7.48026 \\
\hline 125.477 & 121.263 & 7.1179 \\
\hline 127.759 & 122.485 & 6.3845 \\
\hline 130.04 & 123.739 & 5.55726 \\
\hline 132.322 & 124.987 & 4.79608 \\
\hline 134.603 & 126.256 & 3.91786 \\
\hline 136.884 & 127.525 & 3.10163 \\
\hline 139.166 & 128.904 & 2.42374 \\
\hline 141.447 & 130.641 & 1.91209 \\
\hline 143.729 & 133.093 & 1.39506 \\
\hline 146.01 & 135.97 & 1.56747 \\
\hline 148.291 & 138.693 & 2.14053 \\
\hline 150.573 & 140.743 & 2.21325 \\
\hline
\end{tabular}

\begin{tabular}{|c|c|c|}
\hline $\begin{array}{l}\text { Site U1338 } \\
\text { splice depth } \\
\text { (m CCSF) }\end{array}$ & $\begin{array}{l}\text { Site U1337 } \\
\text { splice depth } \\
\text { (m CCSF) }\end{array}$ & $\begin{array}{c}\text { Site U1337 } \\
\text { standard deviation } \\
(\mathrm{m})\end{array}$ \\
\hline 152.854 & 142.572 & 2.01456 \\
\hline 155.136 & 144.328 & 1.74694 \\
\hline 157.417 & 145.863 & 1.50946 \\
\hline 159.698 & 147.331 & 1.31029 \\
\hline 161.98 & 148.795 & 1.19271 \\
\hline 164.261 & 150.27 & 1.13018 \\
\hline 166.543 & 151.772 & 1.13323 \\
\hline 168.824 & 153.316 & 1.13758 \\
\hline 171.106 & 154.928 & 1.02027 \\
\hline 173.387 & 156.565 & 0.935048 \\
\hline 175.668 & 158.253 & 0.847408 \\
\hline 177.95 & 159.94 & 0.81594 \\
\hline 180.231 & 161.664 & 0.812485 \\
\hline 182.513 & 163.426 & 0.806787 \\
\hline 184.794 & 165.186 & 0.83375 \\
\hline 187.075 & 166.95 & 0.954526 \\
\hline 189.357 & 168.72 & 1.13948 \\
\hline 191.638 & 170.494 & 1.33343 \\
\hline 193.92 & 172.286 & 1.39258 \\
\hline 196.201 & 174.099 & 1.49169 \\
\hline 198.482 & 175.91 & 1.51038 \\
\hline 200.764 & 177.749 & 1.53017 \\
\hline 203.045 & 179.634 & 1.54687 \\
\hline 205.327 & 181.54 & 1.546 \\
\hline 207.608 & 183.494 & 1.53044 \\
\hline 209.889 & 185.474 & 1.54754 \\
\hline 212.171 & 187.497 & 1.57202 \\
\hline 214.452 & 189.536 & 1.53381 \\
\hline 216.734 & 191.596 & 1.52506 \\
\hline 219.015 & 193.694 & 1.55435 \\
\hline 221.296 & 195.82 & 1.58287 \\
\hline 223.578 & 197.988 & 1.58296 \\
\hline 225.859 & 200.197 & 1.56087 \\
\hline 228.141 & 202.448 & 1.56452 \\
\hline 230.422 & 204.766 & 1.58171 \\
\hline 232.704 & 206.997 & 1.54244 \\
\hline 234.985 & 209.18 & 1.43417 \\
\hline 237.266 & 211.415 & 1.4087 \\
\hline 239.548 & 213.565 & 1.35075 \\
\hline 241.829 & 215.538 & 1.1786 \\
\hline 244.111 & 217.455 & 0.969104 \\
\hline 246.392 & 219.351 & 0.764728 \\
\hline 248.673 & 221.197 & 0.604229 \\
\hline 250.955 & 222.987 & 0.463438 \\
\hline 253.236 & 224.755 & 0.342255 \\
\hline 255.518 & 226.535 & 0.24922 \\
\hline 257.799 & 228.309 & 0.187123 \\
\hline 260.08 & 230.078 & 0.170661 \\
\hline 262.362 & 231.85 & 0.182373 \\
\hline 264.643 & 233.621 & 0.176838 \\
\hline 266.925 & 235.39 & 0.187012 \\
\hline 269.206 & 237.15 & 0.19184 \\
\hline 271.487 & 238.892 & 0.175212 \\
\hline 273.769 & 240.379 & 0.780353 \\
\hline 276.05 & 241.821 & 1.57368 \\
\hline 278.332 & 243.271 & 2.24466 \\
\hline 280.613 & 244.698 & 2.65889 \\
\hline 282.894 & 246.113 & 2.9839 \\
\hline 285.176 & 247.497 & 3.0751 \\
\hline 287.457 & 248.888 & 3.01314 \\
\hline 289.739 & 250.329 & 2.96357 \\
\hline 292.02 & 251.796 & 2.98039 \\
\hline 294.302 & 253.128 & 2.88875 \\
\hline 296.583 & 254.492 & 2.73647 \\
\hline 298.864 & 255.916 & 2.5327 \\
\hline 301.146 & 257.527 & 2.10323 \\
\hline 303.427 & 259.256 & 1.5386 \\
\hline
\end{tabular}


Table T1 (continued).

\begin{tabular}{|c|c|c|}
\hline $\begin{array}{l}\text { Site U1338 } \\
\text { splice depth } \\
\text { (m CCSF) }\end{array}$ & $\begin{array}{l}\text { Site U1337 } \\
\text { splice depth } \\
\text { (m CCSF) }\end{array}$ & $\begin{array}{c}\text { Site U1337 } \\
\text { standard deviation } \\
(\mathrm{m})\end{array}$ \\
\hline 305.709 & 261.048 & 0.994405 \\
\hline 307.99 & 262.908 & 0.530724 \\
\hline 310.271 & 264.867 & 0.184158 \\
\hline 312.553 & 266.98 & 0.679106 \\
\hline 314.834 & 269.445 & 1.02094 \\
\hline 317.116 & 272.787 & 1.11626 \\
\hline 319.397 & 275.827 & 1.55318 \\
\hline 321.678 & 278.464 & 2.01858 \\
\hline 323.96 & 280.767 & 2.35361 \\
\hline 326.241 & 282.757 & 2.3623 \\
\hline 328.523 & 284.546 & 2.0471 \\
\hline 330.804 & 286.361 & 1.69418 \\
\hline 333.085 & 288.17 & 1.41619 \\
\hline 335.367 & 289.992 & 1.2607 \\
\hline 337.648 & 291.852 & 1.28611 \\
\hline 339.93 & 293.722 & 1.46453 \\
\hline 342.211 & 295.598 & 1.52835 \\
\hline 344.492 & 297.494 & 1.58839 \\
\hline 346.774 & 299.408 & 1.52345 \\
\hline 349.055 & 301.338 & 1.51983 \\
\hline 351.337 & 303.324 & 1.59476 \\
\hline 353.618 & 305.311 & 1.73181 \\
\hline 355.899 & 307.318 & 1.87858 \\
\hline 358.181 & 309.385 & 1.91266 \\
\hline 360.462 & 311.514 & 1.79407 \\
\hline 362.744 & 313.676 & 1.56884 \\
\hline 365.025 & 315.859 & 1.18507 \\
\hline 367.307 & 318.107 & 1.12235 \\
\hline 369.588 & 320.487 & 1.34326 \\
\hline 371.869 & 323.015 & 1.78777 \\
\hline 374.151 & 325.592 & 2.17731 \\
\hline 376.432 & 328.24 & 2.3615 \\
\hline 378.714 & 330.71 & 2.50114 \\
\hline 380.995 & 332.819 & 2.56814 \\
\hline 383.276 & 334.6 & 2.4592 \\
\hline 385.558 & 336.255 & 2.38882 \\
\hline 387.839 & 337.795 & 2.43229 \\
\hline 390.121 & 339.282 & 2.72114 \\
\hline 392.402 & 340.718 & 3.04723 \\
\hline 394.683 & 342.084 & 3.51293 \\
\hline 396.965 & 343.474 & 4.06877 \\
\hline 399.246 & 345.058 & 4.75506 \\
\hline 401.528 & 347.128 & 5.90653 \\
\hline 403.809 & 349.429 & 7.1415 \\
\hline 406.09 & 351.809 & 8.10669 \\
\hline 408.372 & 354.004 & 8.58024 \\
\hline 410.653 & 356.231 & 8.78619 \\
\hline 412.935 & 358.726 & 8.72905 \\
\hline 415.216 & 361.744 & 8.07842 \\
\hline 417.497 & 365.319 & 7.2966 \\
\hline 419.779 & 369.666 & 6.90547 \\
\hline 422.06 & 374.539 & 6.75152 \\
\hline 424.342 & 379.513 & 6.88071 \\
\hline 426.623 & 384.391 & 7.07593 \\
\hline 428.905 & 389.02 & 7.27034 \\
\hline 431.186 & 393.111 & 7.47794 \\
\hline 433.467 & 396.293 & 7.36256 \\
\hline 435.749 & 398.789 & 6.89603 \\
\hline 438.03 & 401.076 & 6.58076 \\
\hline 440.312 & 402.83 & 6.53528 \\
\hline 442.593 & 404.295 & 6.7088 \\
\hline 444.874 & 405.567 & 7.07006 \\
\hline 447.156 & 406.73 & 7.54732 \\
\hline 449.437 & 407.896 & 8.04927 \\
\hline 451.719 & 409.227 & 8.44684 \\
\hline 454 & 410.627 & 8.92487 \\
\hline
\end{tabular}

This mapping function is plotted in Figure F9. The three columns contain the depth at Site U1338 (m CCSF), the correlated depth at Site U1337 (m CCSF), and the uncertainty in correlated depth at Site U1337 (1 standard deviation [m]). 
Table T2. Mapping function that correlates depths converted to m CCSF in the downhole density logs of Sites U1337 and U1338. (Continued on next page.)

\begin{tabular}{|c|c|c|}
\hline $\begin{array}{l}\text { Site U1338 } \\
\text { log depth } \\
\text { (m CCSF) }\end{array}$ & $\begin{array}{l}\text { Site U1337 } \\
\text { log depth } \\
\text { (m CCSF) }\end{array}$ & $\begin{array}{c}\text { Site U1337 } \\
\text { standard deviation } \\
(\mathrm{m})\end{array}$ \\
\hline 138 & 128.559 & 2.07607 \\
\hline 139.563 & 130.156 & 1.65262 \\
\hline 141.126 & 131.746 & 1.25769 \\
\hline 142.688 & 133.325 & 0.918699 \\
\hline 144.251 & 134.896 & 0.712893 \\
\hline 145.814 & 136.445 & 0.738443 \\
\hline 147.377 & 137.886 & 0.886192 \\
\hline 148.94 & 139.209 & 1.07082 \\
\hline 150.503 & 140.425 & 1.21886 \\
\hline 152.065 & 141.556 & 1.30077 \\
\hline 153.628 & 142.585 & 1.24014 \\
\hline 155.191 & 143.568 & 1.14488 \\
\hline 156.754 & 144.538 & 1.05357 \\
\hline 158.317 & 145.493 & 0.963895 \\
\hline 159.879 & 146.444 & 0.86491 \\
\hline 161.442 & 147.412 & 0.748289 \\
\hline 163.005 & 148.402 & 0.627226 \\
\hline 164.568 & 149.413 & 0.504916 \\
\hline 166.131 & 150.439 & 0.420832 \\
\hline 167.693 & 151.495 & 0.359971 \\
\hline 169.256 & 152.573 & 0.319189 \\
\hline 170.819 & 153.667 & 0.323905 \\
\hline 172.382 & 154.772 & 0.377227 \\
\hline 173.945 & 155.893 & 0.459405 \\
\hline 175.508 & 157.014 & 0.568588 \\
\hline 177.07 & 158.155 & 0.691072 \\
\hline 178.633 & 159.321 & 0.817906 \\
\hline 180.196 & 160.532 & 0.90395 \\
\hline 181.759 & 161.777 & 0.882583 \\
\hline 183.322 & 163.028 & 0.838265 \\
\hline 184.884 & 164.27 & 0.813164 \\
\hline 186.447 & 165.534 & 0.759095 \\
\hline 188.01 & 166.829 & 0.70772 \\
\hline 189.573 & 168.138 & 0.742354 \\
\hline 191.136 & 169.456 & 0.835022 \\
\hline 192.698 & 170.79 & 0.961559 \\
\hline 194.261 & 172.137 & 1.09583 \\
\hline 195.824 & 173.467 & 1.1459 \\
\hline 197.387 & 174.807 & 1.15388 \\
\hline 198.95 & 176.177 & 1.14531 \\
\hline 200.513 & 177.549 & 1.1646 \\
\hline 202.075 & 178.911 & 1.18783 \\
\hline 203.638 & 180.268 & 1.23973 \\
\hline 205.201 & 181.627 & 1.31885 \\
\hline 206.764 & 182.985 & 1.41871 \\
\hline 208.327 & 184.341 & 1.48215 \\
\hline 209.889 & 185.683 & 1.45326 \\
\hline 211.452 & 187.03 & 1.42295 \\
\hline 213.015 & 188.383 & 1.38628 \\
\hline 214.578 & 189.737 & 1.35069 \\
\hline 216.141 & 191.097 & 1.32165 \\
\hline 217.704 & 192.464 & 1.30171 \\
\hline 219.266 & 193.84 & 1.2794 \\
\hline 220.829 & 195.231 & 1.26414 \\
\hline 222.392 & 196.633 & 1.26202 \\
\hline 223.955 & 198.078 & 1.27643 \\
\hline 225.518 & 199.53 & 1.33012 \\
\hline 227.08 & 200.971 & 1.35111 \\
\hline 228.643 & 202.418 & 1.4043 \\
\hline 230.206 & 203.877 & 1.48772 \\
\hline 231.769 & 205.375 & 1.58104 \\
\hline 233.332 & 206.903 & 1.68751 \\
\hline 234.894 & 208.464 & 1.73471 \\
\hline 236.457 & 210.042 & 1.69035 \\
\hline 238.02 & 211.609 & 1.60061 \\
\hline 239.583 & 213.171 & 1.51723 \\
\hline 241.146 & 214.678 & 1.44541 \\
\hline
\end{tabular}

\begin{tabular}{|c|c|c|}
\hline $\begin{array}{l}\text { Site U1338 } \\
\text { log depth } \\
\text { (m CCSF) }\end{array}$ & $\begin{array}{l}\text { Site U1337 } \\
\text { log depth } \\
\text { (m CCSF) }\end{array}$ & $\begin{array}{c}\text { Site U1337 } \\
\text { standard deviation } \\
(\mathrm{m})\end{array}$ \\
\hline 242.709 & 216.125 & 1.33528 \\
\hline 244.271 & 217.535 & 1.21543 \\
\hline 245.834 & 218.889 & 1.09118 \\
\hline 247.397 & 220.187 & 0.97938 \\
\hline 248.96 & 221.456 & 0.876122 \\
\hline 250.523 & 222.709 & 0.78304 \\
\hline 252.085 & 223.929 & 0.696907 \\
\hline 253.648 & 225.128 & 0.613717 \\
\hline 255.211 & 226.321 & 0.541264 \\
\hline 256.774 & 227.507 & 0.475552 \\
\hline 258.337 & 228.686 & 0.409684 \\
\hline 259.899 & 229.865 & 0.352471 \\
\hline 261.462 & 231.047 & 0.297974 \\
\hline 263.025 & 232.227 & 0.245284 \\
\hline 264.588 & 233.405 & 0.206861 \\
\hline 266.151 & 234.587 & 0.16785 \\
\hline 267.714 & 235.774 & 0.148588 \\
\hline 269.276 & 236.961 & 0.17027 \\
\hline 270.839 & 238.149 & 0.208887 \\
\hline 272.402 & 239.338 & 0.272797 \\
\hline 273.965 & 240.51 & 0.347421 \\
\hline 275.528 & 241.673 & 0.425237 \\
\hline 277.09 & 242.831 & 0.509714 \\
\hline 278.653 & 243.994 & 0.606631 \\
\hline 280.216 & 245.164 & 0.735092 \\
\hline 281.779 & 246.335 & 0.879865 \\
\hline 283.342 & 247.523 & 1.03179 \\
\hline 284.905 & 248.716 & 1.20972 \\
\hline 286.467 & 249.912 & 1.40416 \\
\hline 288.03 & 251.11 & 1.60371 \\
\hline 289.593 & 252.274 & 1.66458 \\
\hline 291.156 & 253.417 & 1.73429 \\
\hline 292.719 & 254.545 & 1.80647 \\
\hline 294.281 & 255.668 & 1.87287 \\
\hline 295.844 & 256.763 & 1.90536 \\
\hline 297.407 & 257.844 & 1.9756 \\
\hline 298.97 & 258.945 & 2.08692 \\
\hline 300.533 & 260.044 & 2.23057 \\
\hline 302.095 & 261.12 & 2.32344 \\
\hline 303.658 & 262.156 & 2.33463 \\
\hline 305.221 & 263.179 & 2.31632 \\
\hline 306.784 & 264.253 & 2.26928 \\
\hline 308.347 & 265.333 & 2.22659 \\
\hline 309.91 & 266.425 & 2.11666 \\
\hline 311.472 & 267.558 & 1.95534 \\
\hline 313.035 & 268.9 & 1.74957 \\
\hline 314.598 & 270.502 & 1.45194 \\
\hline 316.161 & 272.332 & 1.05539 \\
\hline 317.724 & 274.061 & 0.830873 \\
\hline 319.286 & 275.666 & 0.750716 \\
\hline 320.849 & 277.16 & 0.777198 \\
\hline 322.412 & 278.595 & 0.89076 \\
\hline 323.975 & 279.994 & 1.04636 \\
\hline 325.538 & 281.381 & 1.19839 \\
\hline 327.101 & 282.788 & 1.24821 \\
\hline 328.663 & 284.192 & 1.29646 \\
\hline 330.226 & 285.589 & 1.33462 \\
\hline 331.789 & 286.984 & 1.39996 \\
\hline 333.352 & 288.361 & 1.45146 \\
\hline 334.915 & 289.73 & 1.53371 \\
\hline 336.477 & 291.081 & 1.64079 \\
\hline 338.04 & 292.43 & 1.75401 \\
\hline 339.603 & 293.767 & 1.87392 \\
\hline 341.166 & 295.106 & 1.99472 \\
\hline 342.729 & 296.426 & 2.09854 \\
\hline 344.291 & 297.725 & 2.14584 \\
\hline 345.854 & 299.019 & 2.15013 \\
\hline
\end{tabular}


Table T2 (continued).

\begin{tabular}{|c|c|c|}
\hline $\begin{array}{l}\text { Site U1338 } \\
\text { log depth } \\
\text { (m CCSF) }\end{array}$ & $\begin{array}{l}\text { Site U1337 } \\
\text { log depth } \\
\text { (m CCSF) }\end{array}$ & $\begin{array}{c}\text { Site U1337 } \\
\text { standard deviation } \\
(\mathrm{m})\end{array}$ \\
\hline 347.417 & 300.325 & 2.12465 \\
\hline 348.98 & 301.613 & 2.0702 \\
\hline 350.543 & 302.881 & 1.96528 \\
\hline 352.106 & 304.158 & 1.85214 \\
\hline 353.668 & 305.451 & 1.71848 \\
\hline 355.231 & 306.758 & 1.55984 \\
\hline 356.794 & 308.083 & 1.41159 \\
\hline 358.357 & 309.453 & 1.27114 \\
\hline 359.92 & 310.845 & 1.17262 \\
\hline 361.482 & 312.248 & 1.11332 \\
\hline 363.045 & 313.687 & 1.08874 \\
\hline 364.608 & 315.178 & 1.14855 \\
\hline 366.171 & 316.781 & 1.22427 \\
\hline 367.734 & 318.492 & 1.28519 \\
\hline 369.296 & 320.247 & 1.44276 \\
\hline 370.859 & 322.012 & 1.70079 \\
\hline 372.422 & 323.79 & 1.97364 \\
\hline 373.985 & 325.563 & 2.23835 \\
\hline 375.548 & 327.354 & 2.43888 \\
\hline 377.111 & 329.146 & 2.58955 \\
\hline 378.673 & 330.853 & 2.70302 \\
\hline 380.236 & 332.513 & 2.77065 \\
\hline 381.799 & 334.114 & 2.7947 \\
\hline 383.362 & 335.562 & 2.76912 \\
\hline 384.925 & 336.881 & 2.82989 \\
\hline 386.487 & 338.178 & 2.97809 \\
\hline 388.05 & 339.375 & 3.22442 \\
\hline 389.613 & 340.517 & 3.57737 \\
\hline 391.176 & 341.644 & 3.98811 \\
\hline 392.739 & 342.761 & 4.43956 \\
\hline 394.302 & 343.866 & 4.86641 \\
\hline 395.864 & 344.98 & 5.32245 \\
\hline 397.427 & 346.103 & 5.78197 \\
\hline 398.99 & 347.319 & 6.13892 \\
\hline 400.553 & 348.564 & 6.50022 \\
\hline 402.116 & 349.868 & 6.83795 \\
\hline 403.678 & 351.241 & 7.10652 \\
\hline 405.241 & 352.66 & 7.35654 \\
\hline 406.804 & 354.096 & 7.55206 \\
\hline 408.367 & 355.677 & 7.56879 \\
\hline 409.93 & 357.684 & 6.9196 \\
\hline 411.492 & 359.842 & 5.98716 \\
\hline 413.055 & 362.005 & 5.07058 \\
\hline 414.618 & 364.192 & 4.19774 \\
\hline 416.181 & 366.428 & 3.39033 \\
\hline 417.744 & 368.756 & 2.59916 \\
\hline 419.307 & 371.116 & 1.86949 \\
\hline 420.869 & 373.523 & 1.38022 \\
\hline 422.432 & 375.947 & 1.21128 \\
\hline 423.995 & 378.194 & 1.13829 \\
\hline 425.558 & 380.39 & 1.06387 \\
\hline 427.121 & 382.581 & 1.07832 \\
\hline 428.683 & 384.771 & 1.18883 \\
\hline 430.246 & 386.928 & 1.32372 \\
\hline 431.809 & 389.052 & 1.48439 \\
\hline 433.372 & 391.164 & 1.68305 \\
\hline 434.935 & 393.244 & 1.87712 \\
\hline 436.497 & 395.262 & 2.01522 \\
\hline 438.06 & 397.233 & 2.10228 \\
\hline 439.623 & 399.129 & 2.17404 \\
\hline 441.186 & 400.937 & 2.29032 \\
\hline 442.749 & 402.698 & 2.45713 \\
\hline 444.312 & 404.42 & 2.64912 \\
\hline 445.874 & 406.126 & 2.91616 \\
\hline 447.437 & 407.851 & 3.2303 \\
\hline 449 & 409.577 & 3.59081 \\
\hline
\end{tabular}

This mapping function is plotted in Figure F9. The three columns contain the depth at Site U1338 (m CCSF), the correlated depth at Site U1337 (m CCSF), and the uncertainty in correlated depth at Site U1337 (1 standard deviation [m]). 